Type of Article: Research Article

\title{
Study the effect of a single dose long acting progesterone in prevention of post hysterectomy functional ovarian cysts
}

Amr Adel Mansy*

*Department of Obstetrics \& Gynecology, Alexandria University, Egypt
Corresponding author:

Dr. Amr Adel Mansy Lecture, Department of Obstetrics \& Gynecology, Alexandria University, Egypt Mobile No.: +2012-27494992

Email:amrmansy@gmail.com

\begin{abstract}
Background: Approximately 600,000 hysterectomies are performed annually in the United States, and more than one-third of women have had a hysterectomy by age 60 years. The most common diagnoses among women undergoing hysterectomy are uterine leiomyomata, adenomyosis, uterine prolapse and cancer or hyperplasia.

Functional cysts may be single or multiple, may be bilateral and vary in size but generally do not exceed $5.0 \mathrm{~cm}$ in diameter. They are the result of failure of absorption of the fluid in an incompletely developed follicle or anovulation. They are usually asymptomatic unless hemorrhage, rupture or torsion supervenes, in which case symptoms and signs of acute abdomen develop.
\end{abstract}

A progestogen-only injectable contraceptive is a long-acting, reversible contraceptive. A synthetic progesterone, or progestogen, is slowly released into the systemic circulation following intramuscular (IM) or subcutaneous (SC) injection.

Methods: The study included 68 cases who were subjected to open hysterectomy without oophorectomy for benign gynecologic conditions, cases are randomly selected and divided into 2 groups. Group A: 34 cases received a single dose of $150 \mathrm{mg}$ intramuscular depot medroxyprogesterone acetate as Depoprovera ${ }^{\mathrm{R}}$ within 7 to 10 days postoperative and Group B: 34 cases did not receive any medications. A post operative follow up was done every one month for six months postoperative to exclude the development of ovarian cyst by transvaginal and trans-abdominal ultrasound examination.

Result: the statistical analysis of the collected data showed a statistical significance regarding the development of ovarian cysts in the control group.

Conclusion: Single dose long acting progesterone after hysterectomy without oophorectomy is beneficial in prevention of development of simple functional ovarian cysts in women with hormonally active ovaries.

Keywords: long acting progesterone; hysterectomy; functional ovarian cyst.

\section{Introduction}

Approximately 600,000 hysterectomies are performed annually in the United States, and more than one-third of women have had a hysterectomy by age 60 years. ${ }^{(1)}$

The most common diagnoses among women undergoing hysterectomy are uterine leiomyomata $(41 \%)$, adenomyosis $(18 \%)$, uterine prolapse $(15 \%)$, and cancer or hyperplasia (12\%). Other indications for hysterectomy include 
pelvic inflammatory disease, chronic pelvic pain, and pregnancy-related conditions. ${ }^{(2)}$

Functional cysts may be single or multiple, may be bilateral and vary in size but generally do not exceed 5.0 $\mathrm{cm}$ in diameter. They are the result of failure of absorption of the fluid in an incompletely developed follicle or anovulation. They are usually asymptomatic unless hemorrhage, rupture or torsion supervenes, in which case symptoms and signs of acute abdomen develop. ${ }^{(3)}$

Large and multiple cysts may cause pelvic pain, dyspareunia and irregular bleeding. The enlarged ovary may be recognizable clinically or by ultrasonography. ${ }^{(4)}$

Most of functional cysts disappear spontaneously within a few weeks to months. When symptoms are prolonged, stimulation of postovulatory change by taking progesterone will generally help to relieve the condition. ${ }^{(5)}$

If any cyst persists for longer than 3 months, or size increases to $7 \mathrm{~cm}$, the possibility of a neoplastic cyst must be kept in mind. ${ }^{(6)}$

A progestogen-only injectable contraceptive is a long-acting, reversible contraceptive. A synthetic progesterone, or progestogen, is slowly released into the systemic circulation following intramuscular (IM) or subcutaneous (SC) injection. ${ }^{(7)}$

Depo-Provera ${ }^{\circledR}$ is depot medroxyprogesterone acetate (DMPA) aqueous suspension $150 \mathrm{mg}$ in $1 \mathrm{ml}$ formulated for deep IM injection. This is most commonly used; its main mechanism of action is to suppress ovulation. ${ }^{(8)}$

DMPA does not increase the risk of ovarian or endometrial carcinoma and may offer some protection. Contraceptive injections give protection against ectopic pregnancy and functional ovarian cysts, because ovulation is inhibited.

NICE recommends DMPA as a management option for heavy menstrual bleeding. It also improves symptoms of dysmenorrhea and endometriosis. Long-acting progestogen injection does not affect blood pressure. Limited evidence suggests that the severity of the pain of sickle cell crises may be less in women on DMPA. It is a safe option although there is a lack of evidence regarding the risks of venous thrombosis in women with sickle cell disease. In women with epilepsy, frequency of seizures may be reduced while using DMPA. Acne vulgaris, depression and headaches are not associated with the injection. ${ }^{(9,10)}$

Progestogen-only contraception, whether in the form of progestogen-only contraceptive pills (POCPs), depot injections or slow-release implants, has an extremely good safety profile. ${ }^{(11)}$

\section{Objective}

- To evaluate the role of single dose long acting synthetic progesterone in the prevention of post hysterectomy functional ovarian cysts

\section{Patients}

The study included 68 cases who were subjected to open hysterectomy without oophorectomy for benign gynecologic conditions included multiple fibroids, adenomyosis and uterine bleeding due to simple endometrial hyperplasia as confirmed by post operative histopathological evaluation, cases are randomly selected using a closed envelop methods and divided into 2 groups.

All cases signed a well informed consent to declare their participation in the study.

An ethical approval were obtained from the local ethical committee of Alexandria Faculty of Medicine.

\section{Sample Size}

Considering the prevalence of simple ovarian cysts among normal population accounting for about $9 \%$ required sample size was calculated using Epi Info (version 7).

\section{Methods \& Study Groups}

Group A: thirty four cases received a single dose of 150 mg intramuscular depot medroxyprogesterone acetate as Depoprovera ${ }^{\circledR}$ within 7 to 10 days postoperative

Group B: thirty four cases did not receive any medications.

A post operative follow up was done every one month for six months postoperative to exclude the development of ovarian cyst by transvaginal and transabdominal ultrasound examination.

\section{Contra-indications of DMPA}

- Current breast cancer (within the previous five years).

- Current severe impairment of liver function or history of liver adenoma or steroid-induced cholestatic jaundice.

- History of severe arterial disease or very high risk factors - risk of thrombosis and arterial disease may be increased.

- Acute porphyria, even if there is no history of active disease.

- Unexplained vaginal bleeding. 


\section{$\underline{\text { Results }}$}

Age: The age of patients in group A ranges from 44-55 years with a mean of $49.8 \pm 2.9$ years, in group B it ranges from $45-55$ years with a mean of $49.7 \pm 3.3$ years, the calculated $p$ values did not show any statistical significance regarding the age of both groups (table 1).

\begin{tabular}{|l|c|c|c|}
\hline \multicolumn{1}{|c|}{ Age } & Group A $(\mathbf{n}=\mathbf{3 4})$ & Group B $(\mathbf{n}=\mathbf{3 4})$ & P value \\
\hline Range & $44-55$ years & $45-55$ years & 0.951 \\
\hline Mean \pm SD & $49.8 \pm 2.9$ years & $49.7 \pm 3.3$ years & \\
\hline
\end{tabular}

Table (1): age of the study groups.

Indications for hysterectomy: As regard the indications of hysterectomy in the study groups; 12 cases in group A performed hysterectomy due to bleeding and pressure symptoms caused by multiple fibroids in comparison to 9 cases in group B, in group A there were 12 cases diagnosed as adenomyosis and 14 cases in group B, 21 cases in both groups were diagnosed as simple endometrial hyperplasia 10 of the them in group A and the remaining in group B.

The calculated $\mathrm{p}$ value did not show any significant difference between both groups as regards indications for hysterectomy (table 2).

\begin{tabular}{|l|c|c|c|}
\hline \multicolumn{1}{|c|}{ Indications for hysterectomy } & Group A (n-34) & Group B (n=34) & P value \\
\hline Fibroid uterus & $12(35.3 \%)$ & $9(26.5 \%)$ & \\
\hline Adenomyosis & $12(35.3 \%)$ & $14(41.2 \%)$ & 0.540 \\
\hline Simple endometrial hyperplasia & $10(29.4 \%)$ & $11(32.3 \%)$ & \\
\hline Total & $34(100 \%)$ & $34(100 \%)$ & \\
\hline
\end{tabular}

Table (2): indications for hysterectomy in the study groups.

Type of hysterectomy: In both study groups there were 15 cases in each groups were subjected to total abdominal hysterectomy without oophorectomy while 19 cases in each groups were subjected to subtotal or supracervical abdominal hysterectomy without oophorectomy (Table 3).

\begin{tabular}{|l|c|c|c|}
\hline \multicolumn{1}{|c|}{ Type of hysterectomy } & Group A (n-34) & Group B (n=34) & P value \\
\hline Total & $15(44.1 \%)$ & $15(44.1 \%)$ & \multirow{2}{*}{1.000} \\
\hline Subtotal & $19(55.9 \%)$ & $19(55.9 \%)$ & \\
\hline
\end{tabular}

Table (3): Type of Hysterectomy in the study groups.

Ovarian cyst: In group A, there was only one case that developed ovarian cyst of a mean diameter of $42 \mathrm{~mm}$ as measured by trans vaginal ultrasound, the main presentation was pelvic and iliac pain, the cyst was operated on and histopathology diagnosis was serous cystadenoma (non functional ovarian cyst)

In group B, 8 cases developed ovarian cysts with a mean diameter of $43 \pm 8.6 \mathrm{~mm}$ diameter by ultrasound, 2 of them accidentally discovered during routine follow up, 6 cases presented by iliac and pelvic pain and one them was diagnosed as rupture ovarian cyst but did not subjected to surgical interference.

As a management protocol all cases of ovarian cysts in group B received oral progestin in the form norethindrone 5 mg three times daily for two weeks and follow up showed complete resolution of 7 cases, only one case needed to be surgically removed.

The calculated $\mathrm{p}$ value showed a significant statistical difference between both groups as regards development of ovarian cyst, pain and intervention (Tables 4-6).

\begin{tabular}{|c|c|c|c|}
\hline Development of ovarian cyst & Group A (n-34) & Group B $(n=34)$ & $P$ value \\
\hline Yes & $1(2.9 \%)$ & $8(23.5 \%)$ & \multirow{2}{*}{0.013} \\
\hline No & $33(97.1 \%)$ & $26(76.5 \%)$ & \\
\hline \multicolumn{4}{|l|}{ Size (mm) } \\
\hline Range & \multirow{2}{*}{$42 \mathrm{~mm}$} & $28-53 \mathrm{~mm}$ & \multirow{2}{*}{0.024} \\
\hline Mean \pm SD & & $43 \pm 8.6 \mathrm{~mm}$ & \\
\hline
\end{tabular}

Table (4): development of ovarian cyst in the study groups. 


\begin{tabular}{|c|c|c|c|}
\hline Clinical presentation of Ovarian cyst & Group A (n-1) & Group B (n=8) & P value \\
\hline Accidental discovery & $0(0 \%)$ & $2(25 \%)$ & 0.154 \\
\hline Pain & $1(100 \%)$ & $6(75 \%)$ & 0.048 \\
\hline Rupture & $0(0 \%)$ & $1(12.5 \%)$ & 0.317 \\
\hline Torsion & $0(0 \%)$ & $0(0 \%)$ & 1.000 \\
\hline
\end{tabular}

Table (5): Clinical presentation of ovarian cyst

\begin{tabular}{|c|c|c|c|}
\hline Treatment of ovarian cyst & Group A (n-1) & Group B (n=8) & \multirow{2}{*}{ P value } \\
\cline { 1 - 3 } Medical & $0(0 \%)$ & $7(87.5 \%)$ & \multirow{2}{*}{0.006} \\
\hline Surgical & $1(100 \%)$ & $1(12.5 \%)$ & \\
\hline Total & 1 & 8 & \\
\hline
\end{tabular}

Table (6): Treatment of ovarian cyst

Vaginal bleeding: two cases in group B only have experienced a cyclic vaginal bleeding in cases subjected to subtotal hysterectomy; this was not shown in group A, although the calculated $\mathrm{p}$ value did not show any statistical difference between both groups (Table 7).

\begin{tabular}{|c|c|c|c|}
\hline Vaginal bleeding & Group A (n-19) & Group B (n=19) & P value \\
\hline Yes & $0(0 \%)$ & $2(10.5 \%)$ & \multirow{2}{*}{0.154} \\
\hline No & $34(100 \%)$ & $34(89.5 \%)$ & \\
\hline
\end{tabular}

Table (7): Vaginal bleeding in the study groups

\section{Discussion}

Hysterectomies for benign conditions are commonly indicated in hormonally active females as a definitive treatment in cases with multiple fibroids, adenomyosis and endometrial hyperplasia causing vaginal bleeding or pelvic pain after failure of conservative and medical treatment, preservation of ovaries in such cases may be preferred to avoid sudden onset of menopausal symptoms, in cases when supracervical or subtotal hysterectomy was done, they may complain of cyclic bleeding from the remaining endometrial tissue in the cervical stump that may cause patients' anxiety and fear from recurrence of the condition. Many cases might present to the outpatient or emergency departments complaining of pelvic pain and after ultrasound examination the health care provider may discover uncomplicated or complicated simple functional ovarian cyst, as long acting injectable progesterone is used as a long acting contraceptive methods that inhibit ovulation through inhibition of the hypothalamic pituitary ovarian axis so it could be taken prophylactically in such cases with hormonally active ovaries to prevent the development of simple functional ovarian cysts and their further complications.
The study included sixty eight patients who performed and subjected to hysterectomy whether total or supracervical with preservation of both ovaries, all cases included in the study were not medically contraindicated to use long acting depoprovera 150 $\mathrm{mg}$, they were randomly subdivided into two groups each one included thirty four cases, one group (study group) were prescribed long acting depoprovera as one intramuscular injection and the other group were not prescribed the medication, a regular monthly check up for six months was done and results showed that no statistical difference between both groups regarding age, indications for hysterectomy and type of hysterectomy.

The rational for using 6 months follow up depended on the fact that the average return to fertility is 6 to 9 months after the last injection and by 18 months after the last injection, fertility is the same as that in former users of other contraceptive methods ${ }^{(12,13)}$

In the study group only one case that developed a simple cyst that was persistent even after medical treatment using oral progestin and further laparoscopic oophorectomy revealed a diagnosis of ovarian serous 
cystadenoma (non functional cyst), on the other hand, the control group showed 8 cases the developed simple functional ovarian cysts with a size ranged from 28 to $53 \mathrm{~mm}, 2$ of them were accidentally discovered, 6 were presented by severe iliac pain and diagnosed by ultrasound examination and only one of them was diagnosed as rupture ovarian cyst that diagnosed after laparoscopic surgery after oophorectomy and histopathology revealed functional follicular cyst, all uncomplicated cases of the control group were treated medically and condition resolved after follow up, the statistical analysis of the collected data showed a statistical significance regarding the development of ovarian cysts in the control group.

Review of literature did not find any similar studies and all found researches were focusing on the medical treatment of functional ovarian cysts using either progesterone or combined oral contraceptive pills and no studies found to focus on using long acting injectable synthetic progesterone for prophylaxis of functional ovarian cysts after hysterectomies.

In 2014 Grimes DA et al published a systematic review in Cochrane library reviewing the effect of combined oral contraceptive pills (COCs) in treatment of functional ovarian cysts and they concluded that COCs are not better than watchful waiting. ${ }^{(14)}$

\section{Conclusion}

Single dose long acting progesterone after hysterectomy without oophorectomy is beneficial in prevention of development of simple functional ovarian cysts in women with hormonally active ovaries.

Prevention of functional simple cysts development could prevent long term complications as pain and cyclic bleeding from the remaining cervical stump and decrease the risk of further operative interventions.

\section{References}

1. Brandsborg B, Nikolajsen L, Kehlet H. et al. Chronic pain after hysterectomy. Acta Anaesthesiol Scand. 2008;52:327-331.

2. Kives S, Lefebvre G, Wolfman W. et al. Supracervical hysterectomy. J Obstet Gynaecol Can. 2010;32:62-68.

3. Jacobs I, Oram D, Fairbanks J, Turner J, Frost C, Grudzinskas JG. A risk of malignancy index incorporating CA125, ultrasound and menopausal status for the accurate preoperative diagnosis of ovarian cancer. Br J Obstet Gynaecol 1990; 97: 922e9.
4. National Institute for Health and Clinical Excellence. Ovarian cancer: the recognition and initial management of ovarian cancer. NICE clinical guideline 122. London: NICE, 2011.

5. RCPG Green-top guideline 64. Management of suspected ovarian masses in premenopausal women. London: RCOG, 2011.

6. Royal College of Obstetrics and Gynaecologists. The investigation and management of endometriosis. Green-top Guideline No. 24. London: RCOG, 2006.

7. Summary of Product Characteristics (SPC) - DepoProvera $\mathbb{R} 150 \mathrm{mg} / \mathrm{ml}$ injection; Pharmacia Limited, electronic Medicines Compendium, April 2015

8. Heavy menstrual bleeding; NICE Clinical Guideline (January 2007)

9. Wong AY, Tang LC, Chin RK; Levonorgestrelreleasing intrauterine system (Mirena) and Depot Aust N Z J Obstet Gynaecol. 2010 Jun;50(3):273-9.

10. Manchikanti A, Grimes DA, Lopez LM, et al; Steroid hormones for contraception in women with sickle cell disease. Cochrane Database Syst Rev. 2007 Ap: 18;(2):CD006261.

11. Long-acting reversible contraception; NICE Clinical Guideline (October 2005)

12. Hatcher RA (2004). "Depo-Provera Injections, Implants, and Progestin-Only Pills (Minipills)". In Hatcher RA, Trussell J, Stewart FH, Nelson AL, Cates Jr W, Guest F, Kowal D. Contraceptive Technology (18th rev. ed.). New York: Ardent Media. pp. 461-494. ISBN 0-9664902-5-8.

13. Speroff L, Darney PD (2005). "Injectable Contraception". A Clinical Guide for Contraception (4th ed.). Philadelphia: Lippincott Williams \& Wilkins. pp. 201-220. ISBN 0-7817-6488-2.

14. Grimes DA, Jones LB, Lopez LM, Schulz KF. Oral contraceptives for functional ovarian cysts. Cochrane Database of Systematic Reviews 2014, Issue 4. Art. No.: CD006134. DOI: 10.1002/14651858.CD006134.pub5. 